\title{
Trade and International Transport Services: an Analytical Framework
}

\author{
Soamiely Andriamananjara \\ U.S. International Trade Commission
}

\begin{abstract}
International Transport Services (ITS) play an important role in influencing international trade flows. This paper develops an analytical framework in which ITS costs are endogenously determined. It shows that ITS sector liberalization foster international trade very much the same way tariff liberalization does. From a political economy viewpoint, a unilateral liberalization of the sector may not always be politically feasible, and a multilateral agreement can help prop up support for reform. It is further argued that deregulation and competition policy reform are more likely to be feasible if undertaken jointly.
\end{abstract}

- JEL Classification: F12, F23, L91

- Key words: International transport services, trade facilitation, competition policy, deregulation, political economy

\section{Introduction}

Trade barriers play an important role in influencing the scope and scale of international trade flows. Impediments to international trade generally consist of a mix of policy-related barriers (such as tariffs, quotas, or standards), natural barriers (such as time, distance, or language), and barriers associated with the costs of international transport services (ITS). ITS include the numerous services sectors that enable or facilitate international trade in goods. They are the focus of this paper.

\footnotetext{
*Corresponding address: Soamiely Andriamananjara, Office of Economics, U.S. International Trade Commission, 500 E Street SW, Washington, D.C. 20436,USA, Tel: 1-202-205-3252, Fax: 1-202-2052340, E-mail: soamiely@usitc.gov.

(C)2004-Center for International Economics, Sejong Institution, All Rights Reserved.
} 
In this paper, the term "international transport services" is used broadly to denote any service that is useful in accomplishing international merchandise trade. ${ }^{1}$ As goods are exchanged across national borders, demand for services that cater to that trade is likely to be created. The most obvious ITS are air, rail, and maritime transport services which are crucial in physically moving goods from the exporting to the importing country. ${ }^{2}$ Other services such as finance, communication, and some professional services are also often essential in order to complete the international exchange of goods. ${ }^{3}$

ITS are critical in stimulating international merchandise trade and, in many countries, their costs are believed to be far larger than tariffs or trade related duties. ${ }^{4}$ It has been observed that while recent decades have witnessed substantial drops in tariff barriers, commensurate declines in shipping costs have not occurred. ${ }^{5}$ More importantly, this downward stickiness of shipping costs seems to have happened in spite of major technological advances, such as containerization. ${ }^{6}$

This stickiness of shipping costs has been attributed to a mix of public and

'This definition is similar to what Deardorff (2001) calls "trade services", and which he defines as "any service the demand for which arise directly from trade itself, presumably from trade in other industries."

${ }^{2}$ As defined in Fink et al. (2000), maritime transport service itself consists of three different types of activities: international maritime transport (i.e., the actual transportation service which moves a commodity from one port to another), maritime auxiliary services (i.e., the activities related to cargo manipulation in ports and on ships), and port services (i.e., activities related solely to ship management in ports).

${ }^{3}$ Deardorff (2000) provides an excellent discussion of these services. Note that ITS excludes cabotage (i.e., the transportation of goods within the same country). See Francois et al. (1996) for an interesting study of the U.S. cabotage sector.

${ }^{4}$ See Hummels (1999)who finds that freight rates have higher means and variances than tariff rates. See also the works cited in Hummels (2001). One could think of the costs of ITS as broadly represented by the difference between the c.i.f., and the f.o.b. prices but they could also include other components. In this paper, "ITS costs" and "shipping costs" will be (loosely) used interchangeably.

${ }^{5}$ Hummels (2001) provides evidence "indicating substantial increase in the price of liner shipping (which comprises the majority of world trade)."

${ }^{6}$ One of the major advances was the containerization of international trade. Beginning in the late 1950s, the development of standardized containers greatly facilitated the intermodalism of international trade (that is the movement of merchandise from one country to another by more than one transport mode). Generally, the containers had locking mechanisms that could be attached to a truck chassis, a rail car, a crane, or other containers inside a ships hole or on its deck. (Talley, 2000) In the recent past, the largest growth in fleet capacity has been in large containerships their capacity increased 103 percent between 1993 and 1997. (Slater, 2000)

${ }^{7}$ See for example Fink et al. (2000). An interesting hypothesis is that containerization itself could have caused shipping rates to increase, to the extent that it results in greater market concentration and monopoly power of shipping cartels. (Hummels, 2001) 
private factors. ${ }^{7}$ First, restrictive government policies include a variety of cargo reservation schemes, as well as the granting of monopoly rights to providers of ports and auxiliary services. ${ }^{8}$ In many cases, quantitative restrictions and regulations (such as standards, government procurement, or licensing) have been used to severely restrict market access by foreigners. These policies, justified by either political, security, or economic rationales, tend to limit the extent of competition in the ITS sector and keep rates high. ${ }^{9}$

The second factor is private anti-competitive behavior. In general, ITS sectors are dominated by a few large cartels and perfect competition is seldom the rule of the game in determining shipping rates. For instance, global shipping alliances (or conferences) now dominate containership service, utilizing vessel-sharing agreements that offer shippers integrated services, and fixed schedules. ${ }^{10}$ The U.S. liner shipping sector has gradually moved toward consolidation and concentration, often involving mergers (or other types of joint ventures), to meet demand and improve efficiency. In many cases, shipping conferences are given exemptions from national antitrust laws.

Given the importance of ITS costs in total trading costs, ITS sector liberalization may be as important as tariff liberalization in promoting international trade. ${ }^{11}$ This paper develops a simple analytical framework to show how this may be the case. In the process, it investigates how the market structure of the ITS sector affects the responses of shipping costs and other variables to different policy instruments. It also considers some political economy issues associated with the feasibility of undertaking reform programs aimed at liberalizing the ITS sector.

The paper is structured as follows. The next section (Section II) develops an analytical model which captures the main characteristics of the ITS sector. In this framework, international trade, demand for ITS, and the costs of ITS are endogenously determined. In a series of comparative statics exercises, Section III

\footnotetext{
${ }^{8}$ Cargo reservation schemes require that part of the cargo carried in trade with other states must be transported only by ships carrying the national-flag or interpreted as national by other criteria.

${ }^{9}$ Security concerns triggered by the recent terrorist attacks have exacerbated the restrictiveness of these policies in that they have made customs clearance more rigorous and tedious.

${ }^{10}$ See Slater (2000). Talley (2000) reports that the top three container shipping lines (See-Land, Evergreen and Maersk) account for more than 33 percent of the TEU (twenty-foot equivalent unit) transported.

${ }^{11}$ Using simple trade theory, Deardorff (2001) illustrates how liberalization of trade in services can enhance the gains from trade in goods. Francois and Wooton (2001) rightly argue that in terms of market access, many countries would gain far more from squeezing shipping margins than from a reduction in OECD tariff rates.
} 
explores the likely effects of an unilateral liberalization of the ITS sector, as well as those of a tariff liberalization. It is shown that deregulating, or introducing more competition in, the ITS sector fosters international trade very much the same way tariff liberalization does. Section IV adopts a political economy approach, arguing that unilateral liberalization may not always be politically feasible and that a multilateral agreement may sometimes help in spurring support for policy reform. Along the same line, deregulation and competition policy reform are shown to get more political support if undertaken simultaneously. Section V concludes.

\section{A Model of International Transport Services}

This section develop a framework which is useful in thinking about the ITS sector and the different issues mentioned above. Consider a model with two countries (Country 1 and Country 2) and two types of firms (manufacturing and ITS). Conceptually, the story told here consists of two distinct stages. First, imperfectly competitive ITS firms choose their shipping capacities and compete over shipping rates. ${ }^{12} \mathrm{Next}$, given the equilibrium shipping rates set in the previous stage, the manufacturing firms compete in supplying the two countries' goods markets.

One could think of this setup as a Stackelberg game where the ITS firms are the leaders and the manufacturing firms the followers. As is usual in solving multistages games, the latter stage (i.e., the goods-market) will first be characterized in order to determine the behavioral responses of the manufacturing firms to the shipping rates set by the ITS firms in the first stage. Then, the ITS market equilibrium will be described given the ITS firms' knowledge of the manufacturing firms' likely responses.

\section{Goods market}

Assume that there is only one manufacturing firm in each country (Firm 1 and Firm 2, respectively), and that both firms produce goods that are perfect substitutes for each other. ${ }^{13}$ As in Brander and Krugman's (1993) reciprocal-dumping model, the markets in the two countries are perfectly segmented so that each firm regards

\footnotetext{
${ }^{12}$ Kerps and Scheinkman (1983) show that this type of two-stage game typically produces a Cournot outcome.

${ }^{13}$ The duopoly market structure is a simplifying assumption. The model can be extended to a more general oligopoly structure without fundamentally altering the results presented here.
} 
each country as a separate market and chooses the optimal quantity to supply to each country separately. In each market, each firm acts as a Cournot player which maximizes its profit taking the other firm's output as given, and both manufacturing firms choose their quantities simultaneously.

In Country $i$, the aggregate utility is assumed to have a quasi-linear form:

$$
U_{i}=a_{i} Q_{i}-b \frac{Q_{i}^{2}}{2}
$$

where $Q_{i}$ is the total sales of the good, $a_{i}$ is a parameter representing the size of the domestic market, and $b$ reflects the slope of the demand curve (assumed to be identical in the two countries). Utility maximization yields a linear inverse demand function for the manufacturing good:

$$
p_{i}=a_{i}-b\left(Q_{i 1}+Q_{i 2}\right)
$$

where $p_{i}$ is the price of the good in the Country $i$ and $Q_{i j}(j=1$ or 2$)$ is the quantity supplied by the Country $j$ manufacturing firm ( or Firm $j$ ).

In order to cater to Country $i$ 's market, Firm $j$ (where $j \neq i$ ) has to pay a tariff $\left(t_{i}\right)$ to country $i$ 's government and per-unit shipping cost $\left(s_{i}\right)$ to an ITS service provider. Except for production costs, the domestic firm, Firm $i$ does not have to pay anything when supplying its home market. Assume that production costs are represented by a constant marginal cost $c$ for both firms. Firm $i$ maximizes the profits it makes in both countries by solving the following objective function:

$$
\max _{Q i i, Q j i} Q_{i i}\left[a_{i}-b\left(Q_{i i}+Q_{i i}\right)-c\right]+Q_{j i}\left[a_{j}-b\left(Q_{j i}+Q_{j j}\right)-\left(c+t_{j}+s_{j}\right)\right] .
$$

Due to the segmented-market assumption, the Cournot game occurring in each country can be conveniently analyzed individually. Without loss of generality, consider the game taking place in Country 1's market (the game in Country 2 can be constructed by analogy). Simple manipulations of the first-order conditions yield the following reaction functions (i.e., the profit-maximizing output for a given output by the other firm) for Firm 1 (domestic) and Firm 2 (foreign) respectively:

$$
Q_{11}=\frac{a_{1}-c-b Q_{12}}{2 b}, \text { and }
$$




$$
Q_{12}=\frac{a_{1}-\left(c+t_{1}+s_{1}\right)-b Q_{11}}{2 b}
$$

Recalling that $Q_{i j}$ is the quantity supplied to country $i$ by Firm $j$, the above reaction functions indicate that each firms output is negatively related to the other's. Moreover, the foreign firm's output decreases with production costs and trading costs (customs duties and shipping costs). These reaction functions are graphically shown in the upper panel of Figure 1.

Combining (2) and (3) yields the Nash equilibrium output levels in Country 1's good market:

$$
\begin{gathered}
Q_{11}=\frac{a_{1}-c+\left(t_{1}+s_{1}\right)}{3 b} \\
Q_{12}=\frac{a_{1}-c-2\left(t_{1}+s_{1}\right)}{3 b}
\end{gathered}
$$

which are represented by the intersection of the two reaction curves in Figure 1. As one would expect, the model predicts that an increase in trading costs (graphically denoted by an inward shift of the curve $Q_{12}\left(Q_{11} ; t_{1}, s_{1}\right)$ ) increases home production but decreases imports from abroad.

Figure 1. Goods and ITS markets

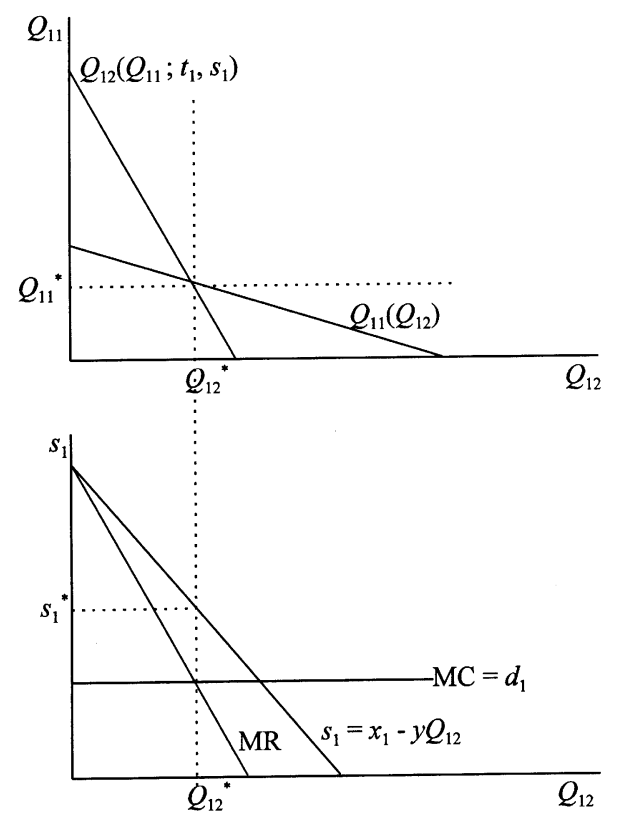




\section{ITS market}

Equations (4) and (5) inform the ITS firms about how the manufacturing firms are likely to react to the shipping rates that are set. Consider now the ITS sector. Assume that $n i$ identical firms compete to "transport" manufacturing goods from Country $j$ to Country $i$ (where $j i$ ). For the sake of simplicity, assume further that in order to operate on that particular trade route, a ITS firm has to get a license from country $i$ 's government. Since this sector is usually dominated by cartels, $n_{i}$ is likely to be small. ${ }^{14}$

The basic framework presented in this part of the paper is somewhat similar to Francois and Wootons (2000) innovative paper which examines the implication of liberalization of the ITS sector for profits, trade and gains from trade. They start with a general equilibrium model (in terms of dual expenditure and revenue functions) to characterize the good market. From that model, they "assume" the export supply and import demand using a second order Taylor-series expansion of the system. ${ }^{15}$ They then use the assumed demand and supply equations to characterize the ITS market in a partial equilibrium model. While this approach is useful in the simulations that they later run, it is rather non-transparent and the linkage between the goods and ITS markets tends to be obscured from an analytical viewpoint. This paper addresses the same issue in a more transparent and compact manner, and augments the analysis using graphical tools. The timing of the rate-setting game is as follows: the ITS firms independently choose shipping capacities, then they compete over prices. This approach is basically the Kerps and Scheinkman (1983) construction, which shows that this type of two-stage (capacity and then price) game typically coincides with the Cournot equilibrium in which quantities are to be interpreted as capacities. ${ }^{16}$

For ease of presentation, the focus will be on the shipping route from Country 2

\footnotetext{
${ }^{14}$ In an abstract way, $n$ could be viewed as representing the degree of competition in the ITS sector. Thus, an increase in $n$ would reflect measures aimed at introducing more competition in the sector. Empirically, this could be represented by a measure similar to the Herfindal index (i.e., the sum of the squares of the market shares) or other concentration indices.

${ }^{15}$ They write: "This amounts to focusing exclusively on the first and second derivatives of $z$ [the net revenue function] and leads to our assuming that import demand and export supply are (approximately) linear."
${ }^{16}$ Francois and Wooton (2000) justify the Cournot setup by arguing that shippers already have large capacities from which they choose to allocate a certain quantity to service a particular trade. This amounts to the ITS firms competing in quantities.


to Country 1 (the other direction could be constructed by analogy). From the viewpoint of the ITS firms, the demand for their services is simply the amount of the manufacturing good shipped by the Firm 2 into Country 1 (or $Q_{12}$ ), given by equation (5), which can also be expressed as a linear inverse demand function:

$$
s_{1}=x_{1}-y n_{1} q_{12}^{i}
$$

where:

$$
\begin{gathered}
x_{1}=\frac{\left(a_{1}-c-2 t_{1}\right)}{2}, \\
y=\frac{3 b}{2},
\end{gathered}
$$

$s_{1}$ is the shipping rate, and $q_{12}^{i}$ is the amount of international transport services supplied by a representative ITS firm (i). Note that since the $n_{1}$ ITS firms are assumed to be identical,

$\mathrm{Q}_{12}=n_{1} q_{12}^{i}$ in equilibrium. This demand for ITS is shown graphically in the lower panel of Figure 1. A decrease in customs duties (i.e., a drop in $t_{i}$ ) is represented by an upward shift in the demand curve.

The marginal cost to the firm of providing shipping services in the direction of Country $i$ is assumed to be constant and is denoted by $d_{\mathrm{i}}$. This represents the "cost of doing business" in the ITS sector, and could reflect the "real" costs of providing the services (e.g., distance), as well as some government policies, such as regulatory burden (e.g., red tape, customs inspection procedures, or standard requirements) or taxes aimed at the ITS companies.

When choosing its capacity for shipping services, a representative ITS firm (i) maximizes the following objective function holding other ITS firms' capacities fixed:

$$
\max _{q_{12}^{i}} q_{12}^{i}\left[x-y\left(q_{12}^{i}+\left(n_{1}-1\right) q_{12}\right)-d_{1}\right]
$$

where

$q_{12}$ is the amount of trade servicing capacity chosen by each of the $\left(n_{1}-1\right)$ other ITS firms. Under the assumed symmetry, the Cournot (Kreps-Scheinkman) equilibrium ITS capacity provision is given by: 


$$
\begin{gathered}
q_{12}^{i}=\frac{\left(x-d_{1}\right)}{y\left(n_{1}+1\right)}, \text { or } \\
Q_{12}=\frac{n_{1}}{\left(n_{1}+1\right)} \frac{\left(x_{1}-d_{1}\right)}{y} .
\end{gathered}
$$

In the lower panel of Figure 1, this quantity is represented by the point where the marginal revenue (MR) intersect to the marginal cost $\left(\mathrm{MC}=d_{1}\right)$. Note that an increase in $n_{1}$ tilts the MR curve counterclockwise, so that, ceteris paribus, increased competition in the ITS sector increases the quantity shipped. By shifting the demand and the marginal revenue curves upward, a decrease in customs duties $t_{1}$ also increases total shipment.

On the figure, the equilibrium shipping rate $s_{1}$ is simply the point on the demand curve that is directly above the MR-MC intersection, or the equilibrium ITS provision. Algebraically, one can use (6) and (7), equating demand and supply, to determine the equilibrium shipping rates, $s_{1}$ :

$$
s_{1}=\frac{x_{1}+n_{1} d_{1}}{n_{1}+1}=\frac{\left(a_{1}-c-2 t_{1}+2 n_{1} d_{1}\right)}{2\left(n_{1}+1\right)}
$$

which is negatively related to $t_{1}$ and $n_{1}$, and positively related to $d_{1} \cdot{ }^{17}$

Having fully characterized the ITS market, it is now useful to go back to the goods market. Given the Nash equilibrium shipping rates given by equation (8), one can express the equilibrium output chosen by each of the two manufacturing firms as functions of $t_{1}, n_{1}$, and $d_{1}$ (using equations (4) and (5)):

$$
\begin{gathered}
Q_{11}=\frac{\left(2 n_{1}+3\right)\left(a_{1}-c\right)+2 n_{1}\left(t_{1}+d_{1}\right)}{6 b\left(n_{1}+1\right)}, \text { and } \\
Q_{12}=\frac{n_{1}\left(a_{1}-c\right)+2 n_{1}\left(t_{1}+d_{1}\right)}{3 b\left(n_{1}+1\right)} .
\end{gathered}
$$

In order to have non-negative quantities, parameter values are restricted such that $a_{1}-c \geq 2\left(t_{1}+d_{1}\right)$ Finally, the price of the good paid by consumers in Country 1 is derived using

\footnotetext{
${ }^{17}$ The negative relationship between to $s_{1}$ and $n_{1}$ holds when that $a_{1}-c \geq 2\left(t_{1}+d_{1}\right)$. This parameter restriction is imposed throughout the paper.
} 


$$
p_{1}=\frac{a_{1}\left(2 n_{1}+3\right)+c\left(4 n_{1}+3\right)+2 n_{1}\left(t_{1}+d_{1}\right)}{6\left(n_{1}+1\right)}
$$

In this model, a government has three main policy instruments that it can use as far as liberalization is concerned: competition policy $(n)$, regulatory policy $(d)$, and trade policy $(t)$.

Reform programs to liberalize the ITS sector could be undertaken either unilaterally or multilaterally. The next two sections look at each type of liberalization. Section III explores the likely impact of an unilateral liberalization of the ITS sector. Section IV looks at the case where the two countries agree to jointly undertake their ITS sector liberalization. It is argued that such a multilateral agreement can make liberalization programs more feasible.

\section{Unilateral Liberalization: Comparative Statics Exercises}

Assuming that Country 1 unilaterally liberalizes its ITS sector, and that Country 2 retains its status quo, this section focuses on Country 1 to investigate the likely effects of each instrument (competition policy, regulatory reform, and trade policy).

\section{Competition Policy}

Consider first the effects of introducing more competition into the ITS sector. $n_{1}$--the number of firms competing in the sectorcan be increased through the elimination of entry barriers, breaking up cartel arrangements, or by guaranteeing market access to new entrants. Increased competition tends to decrease the market power of an individual ITS firm, which in turn shrinks the profit margin that it can capture. The new entrants put a downward pressure on shipping rates, and expand ITS provision.

This is shown graphically in the lower panel of Figure 2. An increase in $n_{1}$ tilts the MR curve counterclockwise, towards the perceived demand curve, so that at any given shipment amount, the gap between the marginal revenue and the shipping price shrinks. The ITS provision expands and shipping rates decline (from point 1 to point 2). As shipping costs drop, the reaction curve of the foreign country shifts outwards (see upper panel of Figure 2). This brings about a decrease in the Country 1 production. However, it can be seen than the increase in foreign production is larger than the drop in home production, so that total supply of the 
Figure 2. Effects of Competition Policy (an increase in $n_{1}$ )

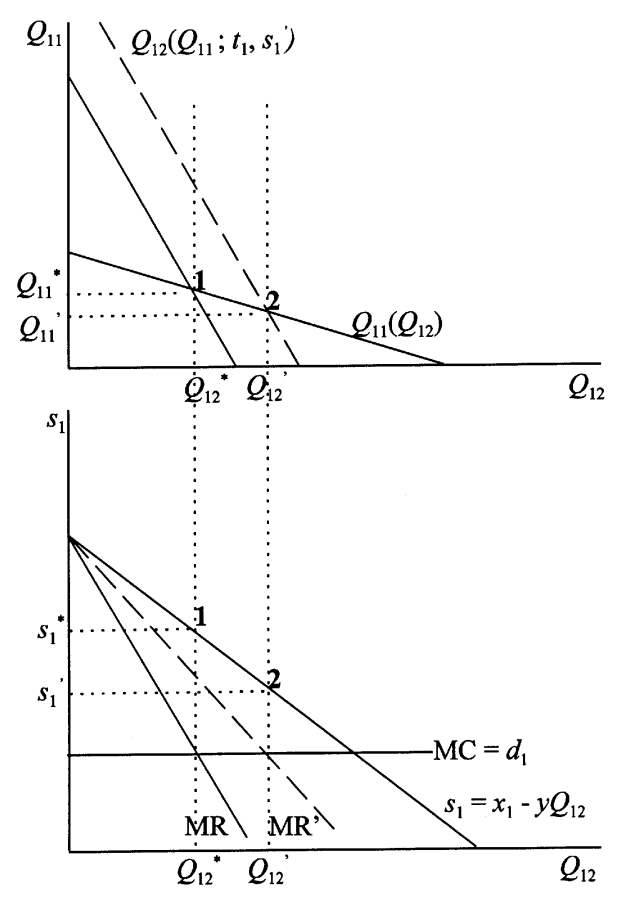

good increases and consumers enjoy lower prices. In short, the competition policy reform benefits mainly the consumers in Country 1 and the manufacturer in Country 2. Incumbent ITS firms as well as the domestic manufacturer are hurt. These effects are maginfied by an increase in the market size, $a_{1}$.

One can also derive those results algebraically:

$$
\begin{aligned}
& \frac{d Q_{12}}{d n_{1}}=\frac{\left(a_{1}-c\right)-2\left(d_{1}+t_{1}\right)}{3 b\left(n_{1}+1\right)^{2}} \geq 0, \\
& \frac{d s_{1}}{d n_{1}}=\frac{\left(a_{1}-c\right)-2\left(d_{1}+t_{1}\right)}{2\left(n_{1}+1\right)^{2}} \leq 0, \\
& \frac{d Q_{11}}{d n_{1}}=\frac{\left(a_{1}-c\right)-2\left(d_{1}+t_{1}\right)}{6 b\left(n_{1}+1\right)^{2}} \leq 0, \\
& \frac{d p_{1}}{d n_{1}}=\frac{\left(a_{1}-c\right)-2\left(d_{1}+t_{1}\right)}{6\left(n_{1}+1\right)^{2}} \leq 0,
\end{aligned}
$$




\section{Regulatory Reform}

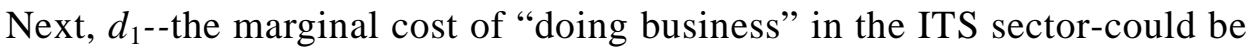
altered through deregulation or by removing the taxes or administrative barriers imposed on ITS companies.

Administrative costs (e.g., complicated customs inspection procedures or operating red tapes) as well as other restrictive measures (e.g., different requirements for different routes) greatly burden ITS companies. ${ }^{18} \mathrm{~A}$ decrease in these measures (e.g., streamlining administrative procedures) leads to a decrease in the cost of ITS provision. Firms will take advantage of the declining marginal costs by expanding their shipping capacities (up to the point where marginal revenue equals the new marginal cost). The increased shipments to Country 1 is accompanied by a drop in $s_{1}$ (see lower panel of Figure 3).

One would note that this effect tends to be larger, the greater is the number of ITS firms or the degree of competition in the sector. When there is only one firm,

Figure 3. Effects of Fiscal or Regulatory Policy (a decrease in $d_{1}$ )
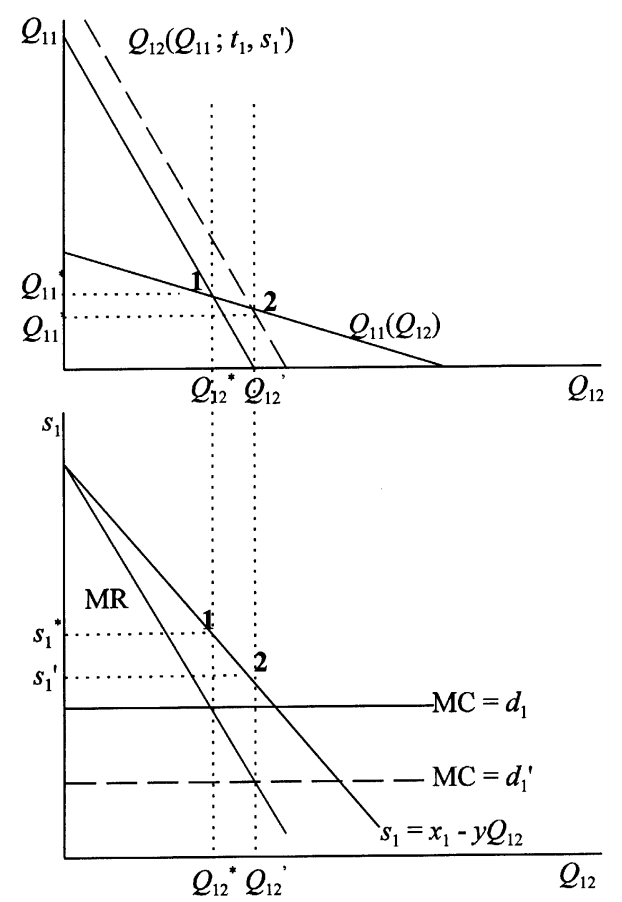

\footnotetext{
${ }^{18}$ Services providers have raised concerns about the imposition of ever expanding technical regulations and standards by industrial countries, as well as the adoption by some developing countries of technical regulations that have no real scientific basis (Messerlin and Zarrouk, 1999).
} 
only one half of the cost decrease is passed on to users in form of ITS rate decline. ${ }^{19}$ However, for larger $n_{1}$, most of the change is passed through to users. On the upper panel of Figure 3, the decrease in the ITS costs associated with deregulation shifts the reaction curve of the foreign firm outward: foreign output rises while home production decreases. As in the case of competition policy, the increase in foreign production is larger than the decline in home production: total supply of the good increases and consumers pay lower prices. In this case, the regulatory policy reform benefits mainly the consumers in Country 1 , the manufacturer in Country 2 , and the ITS firms. The domestic manufacturer becomes worse off.

Algebraically, one can derive:

$$
\begin{aligned}
\frac{d Q_{12}}{\mathrm{~d} d_{1}} & =\frac{2 n_{1}}{3 b\left(n_{1}+1\right)}<0, \\
\frac{d s_{1}}{\mathrm{~d} d_{1}} & =\frac{n_{1}}{\left(n_{1}+1\right)}>0, \\
\frac{d Q_{11}}{\mathrm{~d} d_{1}} & =\frac{n_{1}}{3 b\left(n_{1}+1\right)}>0, \\
\frac{d p_{1}}{\mathrm{~d} d_{1}} & =\frac{n_{1}}{3\left(n_{1}+1\right)}>0 .
\end{aligned}
$$

\section{Trade Policy}

One of the most interesting results of this model is that trade liberalization in the form of a decrease in tariff $\left(t_{1}\right)$ will lead to an increase in the shipping costs. ${ }^{20} \mathrm{By}$ increasing the demand for merchandise trade, trade liberalization increases the demand for international transport services. This shows up as an upward shift in the demand and MR curves (see lower panel of Figure 4). As expected, increased demand tend to push price upwards, so that the ITS firms end up charging higher rates. This effect will be strongest when the number of ITS firms is small (i.e., MR is steeper when $n_{1}$ is small).

In spite of the rates hike, however, total trading costs from Country 2 to Country 1 (customs duties plus shipping cost, or $t_{1}+s_{1}$ ) still declines. The drop in trading cost is associated with an outward shift in the Firm 2's reaction curve (upper panel

\footnotetext{
${ }^{19}$ Graphically, this is due to the fact that the slope of the demand curve is half of that of the marginal revenue curve.

${ }^{20} \mathrm{~A}$ similar result was derived in Francois and Wooton (2000).
} 
Figure 4. Effects of Trade Policy (a decrease in $t_{1}$ )

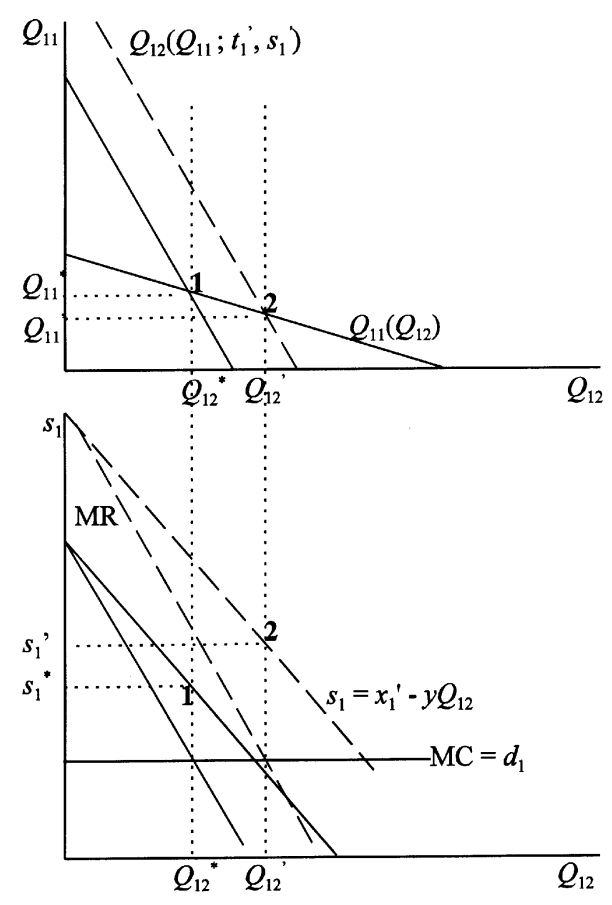

in Figure 3). Again, foreign output rises while home production decreases. The effect of a tariff cut on international trade is larger when there is more competition in the ITS sector. Finally, since the increase in foreign production is much larger than the decline in home production, total production increases and consumer price declines. In this case, the trade liberalization benefits the consumers in Country 1, the manufacturer in Country 2, and the ITS firms, if the latter have market power. The domestic manufacturer is hurt by the liberalization.

These results can also be derived algebraically:

$$
\begin{aligned}
\frac{d Q_{12}}{\mathrm{~d} t_{1}} & =\frac{2 n_{1}}{3 b\left(n_{1}+1\right)}<0, \\
\frac{d s_{1}}{\mathrm{~d} t_{1}} & =\frac{-1}{\left(n_{1}+1\right)}<0, \\
\frac{d Q_{11}}{\mathrm{~d} t_{1}} & =\frac{n_{1}}{3 b\left(n_{1}+1\right)}>0, \\
\frac{d p_{1}}{\mathrm{~d} t_{1}} & =\frac{n_{1}}{3\left(n_{1}+1\right)}>0 .
\end{aligned}
$$


One would note that in terms of trade volume, domestic production and price, the effects of trade liberalization (a decrease in $t_{1}$ ) are algebraically equivalent to those of a regulatory reform aimed at decreasing the "costs of doing business" in the ITS sector (a decrease in $d_{1}$ ). This suggest that deregulation of the ITS sector could be as important as conventional tariff reduction in customs duties for merchandise trade. ${ }^{21}$

\section{Multilateral Liberalization: Some Political Economy Considerations}

It can be rigorously shown that the policy experiments described in the previous section positively affect the country's aggregate welfare. However, while they clearly benefits some groups, they also produce losers. As a matter of fact, an unilateral competition policy reform was shown to be beneficial to the domestic consumers and the foreign manufacturer, but it also hurts the incumbent ITS firms as well as the domestic manufacturer. Also, deregulation of the ITS sector hurts the domestic manufacturer but benefits the domestic consumers, the foreign manufacturer, and the ITS firms.

These results yields a number of interesting political economy implications. For instance, the model predicts that ITS firms would tend to favor regulatory reforms (i.e., reforms that reduce the "costs of doing business") and oppose competition policy reforms. Another implication is that if the domestic manufacturer had large enough political clout, they may be able to derail a reform program at the expense of the other players.

This section considers this second implication and argues that policy reforms that are not politically feasible unilaterally could become possible if undertaken in the context of a multilateral agreement. ${ }^{22}$ In such an agreement, Country 1 and Country 2 agree in concert to simultaneously pursue their reform programs. The intuition is that, while Firm 1 (Country 1's manufacturer) loses from Country 1's reform, it also gains from Country 2's liberalization so that, on the whole, it would support the agreement. Analogously, Firm 2 (Country 2's manufacturer) will

\footnotetext{
${ }^{21}$ Of course, one difference would always remain in that while it is possible to reduce tariffs $\left(t_{1}\right)$ to zero, doing the same with ITS costs $\left(d_{1}\right)$ is impossible.

${ }^{22} \mathrm{~A}$ multilateral agreement could also be helpful to lock in domestic reforms, as the reciprocity involved in them often offers useful international discipline and enforcement mechanisms. Note that the same argument can be used in support of a multilateral tariff liberalization.
} 
support the agreement if the benefits it gets from the improved access to Country 1's market more than offset the losses from more competition from Firm 1 in the its own market.

To demonstrate, consider the profits that Firm 1 makes in each country. In Country 1, its (domestic) profits can be expressed as follows:

$$
\Pi_{11}=\frac{\left(\left(2 n_{1}+3\right)\left(a_{1}-c\right)+2 n_{1}\left(t_{1}+d_{1}\right)\right)^{2}}{36 b\left(n_{1}+1\right)^{2}}
$$

This expression is positively related to $d_{1}$, but is negatively related to $n_{1}{ }^{23}$ Thus, Firm 1 is hurt by a domestic regulatory reform that decreases the (marginal) cost of providing ITS or by an increase in the degree of competition in the ITS sector. Assuming that the manufacturer is organized well enough to be able to influence policy-making, it would oppose such policy measures because they tend to stimulate competition from Firm 2.

On the other hand, Firm 1's profits in Country 2's market can be expressed as:

$$
\Pi_{21}=\frac{\left(n_{2}\left(a_{2}-c\right)+2 n_{2}\left(t_{2}+d_{2}\right)\right)^{2}}{9 b\left(n_{2}+1\right)^{2}}
$$

The above expression shows how Firm 1 is affected by liberalization programs undertaken by Country 2's government. A close inspection reveals that this expression is negative in $d_{2}$ but positive in $n_{2}$. That is, Firm 1 benefits from measures undertaken by Country 2 to decrease the marginal cost of providing international transport services or to increase the degree of competition in the ITS sector. It will support such measures as they improve its access to Country 2's market by reducing ITS rates.

Will Firm 1 support a multilateral agreement in which Country 1 and Country 2 agree to simultaneously liberalize their international transport services market? The answer depends on the relative strength of the two opposing forces that affect the firm's total profits. For tractability, assume that the two countries are initially exactly alike in terms of policy (i.e., $t_{1}=t_{2}=t, n_{1}=n_{2}=n$, and $d_{1}=d_{2}=d$ ). In order to study how size asymmetry might affect incentives for reform, it is assumed, without loss of generality, that Country 1's market is larger than Country 2 's by a factor of ( (i.e., $a_{1}=a$, and $a_{2}=a$, where $(\gamma)$. Thus, the total profits of Firm

\footnotetext{
${ }^{23}$ Recall that throughout the paper, the parameter values are restricted such that $a-c \geq 2(t+d)$.
} 
1 (i.e., the sum of (12) and (13)) are expressed as:

$$
\Pi_{1}=\frac{((2 n+3)(\gamma a-c)+2 n(t+d))^{2}}{36 b(n+1)^{2}}+\frac{\left(n\left(a_{2}-c\right)+2 n(t+d)\right)^{2}}{9 b(n+1)^{2}} .
$$

Firm 1 will support a multilateral agreement as long as its gains from Country 2's reforms offset its losses from Country 1's. The above expression offers some interesting implications regarding the interaction between competition policy reform and regulatory reform.

\section{Competition Policy}

Consider first the effect of a multilateral agreement on competition policy (i.e., a simultaneous increase in $n$ by Country 1 and Country 2) on Firm 1's total profits: ${ }^{24}$

$\frac{d \Pi}{d n}=\frac{-[(a \gamma-c)-2(d+t)][(a \gamma-c)(3+2 n)+2 n(d+t)]}{18 b(1+n)^{3}}+\frac{4 n[(a-c)-2(d+t)]^{2}}{18 b(1+n)^{3}}$

A multilateral agreement on competition policy decreases the ITS rates on both trading routes (from Country 1 to Country 2, and the opposite direction), so that, on the export front, Firm 1 benefits from better market access in Country 2 but, domestically, it loses from the increased competition from Firm 2. In fact, one can verify that the first term (the change in domestic profits) above is negative and the second one (the change in export profits) is positive.

Accordingly, the sign of the above expression (14) is generally ambiguous.

For some parameter values, Firm 1's gains in the export market would exceed its losses in the domestic market and expression (14) would be positive. This is more likely to happen when the values of $d$ and $t$ are small. That is, when trading costs $(d$ and $t$ ) are low, Firm 1 is more likely to support an increase in $n$ by both countries. Figure 5 illustrates this result. The " $\mathrm{d} P i_{1} / \mathrm{d} n=0$ " curve traces the "policy pairs" ( $d$ and $n$ ) for which the firm is indifferent about the agreement (i.e., it neither gains nor loses). For policy pairs in the upper-left side of the curve (low

\footnotetext{
${ }^{24}$ This may, for example, take the form of an international agreement to end the exemption of collusive agreements in the ITS sector from national competition law. This could also be an agreement to allow foreign service providers to operate on incoming trading routes.
} 
$d$ /high $n$ ), the firm would support the agreement. In the lower-right side of the indifference curve, the agreement would be rejected. Thus, regulatory reform (a decrease in $d$, or a leftward horizontal movement) might help in rallying support for an agreement on competition policy reform if it is enough to move the existing policy pair from the "reject" to the "support" area. Intuitively, by removing some of the ex-ante trade impediments, deregulation may offer the manufacturer more to gain (as an exporter) and less to lose (in the domestic market) from the agreement. A tariff liberalization (a decrease in $t$ ) would shift the "indifference curve" to the right, thereby increasing the likelihood of the current policy pair to be located in the larger "support" area.

Concerning size asymmetry, the right hand side of (14) is inversely related to the size of the domestic market $(\gamma)$ : larger market size means that the domestic manufacturer has more to lose from a competition policy reform and, hence, is more prone to oppose such an agreement. In Figure 5, a larger domestic market is represented by a right shift in the indifference curve, or a decrease in the area under which the agreement is supported.

\section{Regulatory Reform}

A similar story can be told about a multilateral agreement on regulatory policy pertaining to the ITS sector (i.e., a simultaneous decrease in $d$ by Country 1 and Country 2). ${ }^{25}$ The effect of such agreement on Firm 1's profits is written as:

Figure 5. Incentives for Multilateral Competition Policy Agreement (a increase in $n$ )

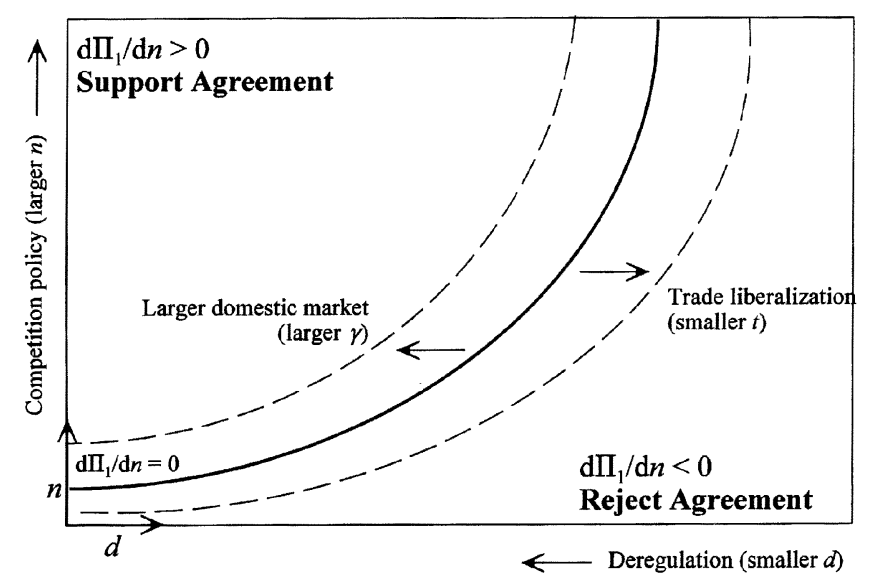

\footnotetext{
${ }^{25}$ This could take place as a simultaneous and reciprocal deregulation, or an harmonization of ITS rules and procedures between the two countries.
} 


$$
\frac{d \Pi_{1}}{d d}=\frac{n[(a \gamma-c)(3+2 n)+2 n(d+t)]}{9 b(1+n)^{2}}-\frac{4 n^{2}[(a-c)-2(d+t)]}{9 b(1+n)^{2}} .
$$

Simultaneous ITS sector deregulation lowers the ITS rates, and boost merchandise trade going in both directions. Firm 1 loses domestically (positive first term in (15)), but benefits in the export market (negative second term), so that the overall effect on total profit is ambiguous. Under some parameter values, the former effect will be dominated by the second one. Figure 6 provides an illustration for this. As in the previous subsection, the " $\mathrm{d} P i_{1} / \mathrm{d} d=0$ " curve denotes the $d$ and $n$ pairs for which the firm is indifferent about the multilateral agreement. For the policy pairs in the upper-left side of the indifference curve (low $d$ /high $n$ ), the firm stands to gain from the agreement and will support it. The agreement will be opposed in the area to the lower-right of the curve.

An increase in $n$ (an upward vertical movement) might be helpful in switching the policy pair from the "oppose" to the "support" area. In other words, multilateral deregulation is likely to be supported by Firm 1 when the degree of competition in the ITS sector is high. Intuitively, by reducing the initial trade costs, de-cartelization enhance the potential export effects of the (reciprocal) deregulation. At the same time, trade liberalization shifts the "indifference curve" south-east-ward, thereby expanding the "support" areathe $d$ and $n$ pairs for which the agreement would be supported.

One can also demonstrate that expression (15) is negatively related to $(\gamma)$. That is, the larger is a country's domestic market size, the less likely it is to support a multilateral agreement on regulatory policy in the ITS sector. This is driven by the first term on the RHS of (15): larger market size means that the domestic manufacturer has more to lose from a liberalization program. On Figure 6, a larger domestic market is represented by a left shift in the indifference curve, or a smaller "support" area.

One could draw a couple of conclusions out of this section. First, regulatory and competition policy reforms that are not politically feasible in an unilateral manner, could be achieved in the context a multilateral agreement which uses reciprocal liberalization as a way to placate potential losers. Second, in terms of political support, regulatory and competition policy reforms are strategic complement. That is, undertaking one could increase support for (or lessen resistance to) the other. Thus, undertaking them simultaneously makes them more politically achievable than undertaking them separately. Third, undertaking tariff liberalization might help in gathering 
Figure 6. Incentives for Multilateral Deregulation Agreement (a decrease in $d$ )

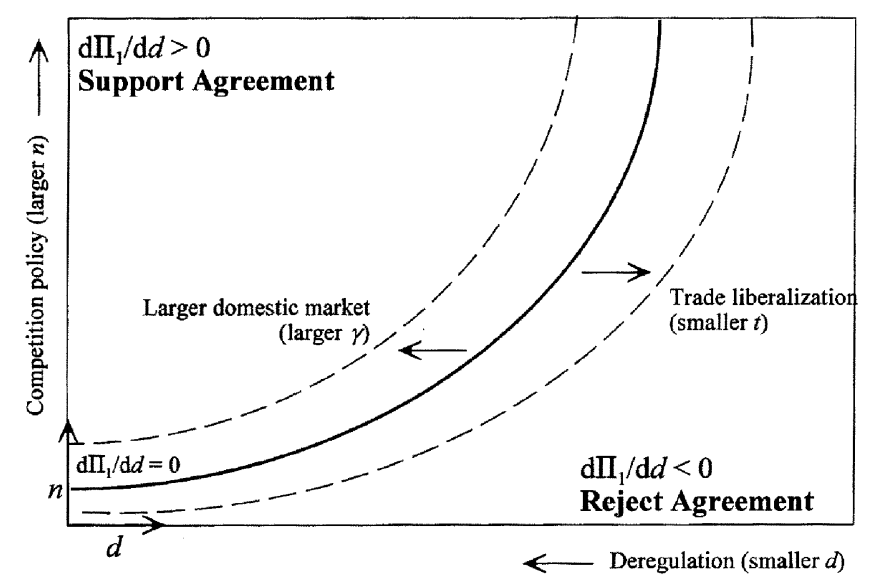

support for a multilateral agreements to liberalize the ITS sector. Finally, larger countries tend to be less supportive of such an agreement.

\section{Conclusion}

As far as impediments to merchandise trade are concerned, costs associated with international transport services can be a substantial fraction of the total trading costs that traders have to pay. In magnitude, they are usually believed to be much larger than the costs associated with customs duties or tariff-rate-quotas. Using a simple analytical model and standard graphical tools, this paper develops a framework to think about international transport services and their relations with goods trade.

To the extent that the ITS sector is dominated by a limited number of cartels, measures that instill more competition (by increasing the number of players) could yield substantial increases in good trade. It is also shown that measures aimed at decreasing the cost of providing ITS can be as important as more traditional trade liberalization through tariff cuts. One interesting result is that trade liberalization could lead to an increase in shipping rates, as the liberalized trade tend to increase demand for international transport services. This effect tends to be larger, the smaller the number of firms competing in the ITS sector.

A number of illustrations of these results can be found in the literature. For instance, it has been estimated that open-skies agreements (which increase the number of airlines competing over particular routes) have lowered fares to 
consumers by approximately 14 percent (Larson 2000). Similarly, Hoekman and Braga (2000) report that liberalization of flag discrimination led to substantial diversification of Chilean exporters away from domestic shipping lines, allowing products to be shipped at significantly lower costs. Also the elimination of barriers to competition in the provision of port services in Chile and Mexico led to substantial reductions in shipping costs (by almost 50 percent).

Fink et al. (2001) estimate that the breakup of private carrier agreement cartels would cause a reduction in liner transport prices by one-third and to cost savings of up to $\$ 3$ billion on goods carried to the U.S. alone. Although this paper does not address within country trade, it is useful to cite Francois et al. (1996) who study the Jones Act (which prohibit foreign shipping firms from transporting goods between two U.S. locations) and estimate that a welfare gain of around $\$ 3$ billion a year could be obtained by letting foreign shipping firms operate on domestic routes.

Since they are likely to impose some costs on some domestic interests, reform programs aimed at liberalizing the ITS sector may not be feasible on an unilateral basis. This paper offers some interesting political economy considerations with regards to the feasibility of such programs. In particular, it demonstrates the existence of a kind of strategic complementarity between different types of liberalization. Regulatory and competition policy reforms that are not politically feasible in an unilateral manner, could be achieved in the context a multilateral agreement, especially if they are undertaken jointly: competition policy reform could help make regulatory reform politically sustainable and vice versa. Trade reform could also be useful in rallying support for such an agreement. Finally, it was shown that larger countries tend to be more reluctant to support a multilateral agreement to liberalize the ITS sector since they have more to lose from such an initiative. This result may explain why the United States has not been not very keen on including (maritime or air) transport services in the next round of negotiations or addressing it under the build-in GATS agenda.

\section{Acknowledgements}

Thanks are due to Michael Ferrantino, Russell Hillberry, Jong Eun Lee, Rodney Ludema, Marcelo Olarreaga, Chris Snyder, and seminar participants at the Georges Washington University for useful comments. This paper does not represent in any way the views of the International Trade Commission, its 
individual commissioners, or other Commission staff.

Received 5 December 2003, Accepted 6 March 2004

\section{References}

Brander, James and Paul Krugman (1983) "Reciprocal Dumping Model of International Trade," Journal of International Economics, 15, 313-21.

Deardorf, Alan V. (2001) "International Provision of Trade Services, Trade, and Fragmentation," Review of International Economics, 9(2), 233-48.

Fink, Carsten, Aaditya Mattoo, and Ileana Cristina Neagu (2001) "Trade in International Maritime Services: How Much Does Policy Matter," World Bank Policy Research Working Paper No. 2522.

Francois, Joseph F., Hugh Arce, Kenneth Reinert and Joseph Flynn (1996) "Commercial Policy and the Domestic Carrying Trade: A General Equilibrium Assessment of the Jones Act," Canadian Journal of Economics, 29(1).

Francois, Joseph F., and Ian Wooton (2001) "Trade in International Transport Services: The Role of Competition," Review of International Economics, 9(2), 249-261.

Hoekman, Bernard and Carlos A. Primo Braga (1997) "Protection and Trade in Services," World Bank Policy Research Working Paper No. 1747.

Hummels, David (1999) “Towards a Geography of Trade Costs," Working Paper, Purdue University.

Hummels, David (2001) "Have International Transportation Costs Declined?" Working Paper, Purdue University.

Kerps, David M. and Jose A. Scheinkman (1983) "Quantity Pre-Commitment and Bertrand Competition Yield Cournot Outcomes," The Bell Journal of Economics, 14, 326-37.

Messerlin Patrick A. and Jamel Zarouk (1999) "Trade Facilitation: Technical Regulations and Customs Procedures," presented at the WTO/World Bank Conference on Developing Countries in a Millennium Round, Geneva, 20-21 September 1999.

Slater, Rodney E. (2000) "Transportation: The Key to Globalization," Economic Perspectives, International Transportation: Moving The Global Economy Forward, 5(3).

Talley, Wayne K. (2000) "Ocean Container Shipping: Impact of a Technological Improvement," Journal of Economic Issues, 34(4), 933-48. 